\title{
Fatigosa irrupción de los derechos sociales fundamentales de los trabajadores en el espacio de la Unión Europea
}

\author{
Manuel M. ${ }^{a}$ Zorrilla Ruiz \\ Catedrático Emérito de la Universidad de Deusto \\ Ex-Presidente del Tribunal Superior de Justicia del País Vasco \\ Presidente de la Asociación de Jueces y Magistrados Jubilados de España
}

Recibido: 21.06.2010

Aceptado: 30.06 .2010

\begin{abstract}
Resumen: Las naciones democráticas del mundo occidental acogieron, a mediados del siglo Xx, los nuevos derechos fundamentales reconocidos a los trabajadores. La emergencia de la Europa de las Comunidades se debió a predilecciones económicas que relegaron a un segundo plano los aspectos relativos a la Política Social y el Derecho Social. Tras el impulso debido al Acta Única Europea, el Tratado de la Unión Europea y el Tratado de Ámsterdam proclamaron la necesidad de una protección social adecuada. Esos derechos básicos -incorporados a la lista de la Carta de Derechos Fundamentales de la Unión Europea aprobada en el Tratado de Niza- afluyeron después al Proyecto de Tratado que establecía una Constitución para Europa y que se vio frustrado por falta de ratificación. El Tratado de Lisboa atribuyó, al fin, carácter vinculante a dicho repertorio. El porvenir de los derechos estudiados depende, entre otros condicionamientos, de la coincidencia pacífica en definir el concepto de integración europea y del signo de las vicisitudes económicas en curso.
\end{abstract}

Palabras clave: Derechos sociales, Política Social, protección social adecuada, recepción constitucional, porvenir.

Abstract: The democratic nations of the occidental world received, in the middle of 20th century, the new fundamental rights recognized to the workers. The foundation of the European Communities was due to economic preferences and placed in a secondary level the questions concerning to the Social Politic and the Social Law. After the impulse due to the Single European Act, the Treaty of the European Union and the Treaty of Amsterdam proclaimed the pressure of an adequate social protection. Those basic rights -included in the list of Fundamental Rights for the European Union-were accepted by the Project of the European Constitution, which was not ratified. The Treaty of Lisbon declared the direct effect of this enunciation. The future of the inspected rights depends on the pacific coincidence about the meaning of the European integration and on the sign of the successive economic events.

Key words: Social rights, Social Politic, social protection, constitutional reception, future.

Sumario: 1. Generación e inspiración del Derecho Social europeo.2. Carácter y variedad significativa de la Política Social europea.- 
3. Individualización sociopolítica del espacio social europeo.-4. Predominio del carácter estrictamente armonizador y escasamente innovador de la Política Social comunitaria.-5. Proliferación de los esfuerzos transformadores de adelanto y acceso a la tierra prometida de la Europa Social.-6. Emergencia y perfil fisonómico de la Unión Europea.7. Aclaración de las opacidades y otros inconvenientes del laberinto normativo comunitario.-8. Irrupción intensiva del tema de los derechos sociales fundamentales de los trabajadores.-9. Estado de cosas anterior al Proyecto de Tratado por el que se establece una Constitución para Europa.-10. Circunstancias que acompañan a la preparación y perfección del Tratado de Lisboa.-11. ¿Futuro postlisboeta indefinido de la UE respecto a los derechos fundamentales de los trabajadores?

\section{Generación e inspiración del Derecho Social europeo}

El Derecho Social europeo regula las relaciones individuales y colectivas de trabajo y la acción protectora de los regímenes públicos de Seguridad Social que comparten los respectivos sectores del ordenamiento jurídico comunitario. Este conjunto emana de una Política Social cuyas aspiraciones -de tradición cristiana y secular- se acentuaron a causa de las necesidades creadas por las circunstancias económicas y el estado de cosas subsiguiente a la 2. ${ }^{a}$ Guerra Mundial. Aunque el ámbito actual del Derecho Social europeo es el propio de la UE (Unión Europea), las mudanzas y la velocidad de crucero de su proceso evolutivo se han señalado por el enfrentamiento -álgido y velado- de los intereses económicos y las crecientes reivindicaciones del sindicalismo occidental. Sustituyendo sus proyectos revolucionarios por las opciones de concertación y de diálogo, los sindicatos desecharon la utopía de derrocar el modelo del Estado de las libertades y escenificar el fin de la Historia consiguiente a la dictadura del proletariado.

Las fricciones entre lo inexorable de las voluntades políticas y el intelectualismo de la naturaleza de las cosas han impreso carácter a los momentos notables del Derecho Social europeo y explicado lo irreductible de las contradicciones que el manejo esmerado de la técnica jurídica no ha conseguido eliminar.

La traslación de las adquisiciones de la extinta Economía de la Guerra a los dominios de la prometedora Economía de la Paz añadieron a los problemas de la competencia industrial y mercantil otras cuestiones requeridas de respuestas urgentes. Los amagos de la crisis -que hacía, en Europa, sus primeras armas- lo demostraban y exigían. Las reconversiones industriales -sobre todo, las de orden tecnológico- pusieron en boga ingeniosos ciclos productivos que, para mitigar la destrucción del empleo, marginaban las ofertas obsoletas e incentivaban las demandas de los nuevos bienes y servicios en los mercados de libre competencia. Las readaptaciones profesionales acomodaron a esas novedades el concurso de la fuerza de trabajo y res- 
tauraron el equilibrio roto en una economía general que ansiaba ir en busca del norte perdido.

El principio de estabilidad en el empleo -peculiar de las etapas de bonanza económica castigadas por la inminencia de las crisis que se avecinaban- garantizaba la conservación de las categorías profesionales de cada rama o sector de la producción, la promoción de los trabajadores mientras subsistiesen sus relaciones contractuales, la identidad de las prestaciones constitutivas de la fuerza de trabajo y la configuración del derecho al trabajo como un derecho absoluto del que se era titular por tiempo indefinido. El principio de continuidad en el empleo se convirtió en una servidumbre inseparable de la fisonomía económica de la Europa posbélica. Innovaba, ante las intuiciones de la crisis, la figura del puesto de trabajo -expuesto a la variación de sus contenidos esenciales por imperio de la organización productiva que se reforzaba- y concebía el derecho subjetivo al trabajo como un derecho relativo de obligación que podía extinguirse sin perjuicio del resarcimiento de los daños causados a su titular.

La población activa -favorecida por el juego del principio de estabilidad en el empleo- constaba de una mayoría de trabajadores ocupados y una minoría residual de trabajadores disponibles. Conforme al canon de continuidad en el empleo, dicha población incluía, de una parte, a los trabajadores adscritos a los procesos productivos regularizados y, de otra, a los desempleados que percibían prestaciones públicas o cuyas tareas de perfeccionamiento y/o formación les permitían incorporarse a las actividades transformadas por las reconversiones industriales.

\section{Carácter y variedad significativa de la Política Social europea}

La crudeza de la identidad capitalista del modelo europeo que se prefería supeditaba los esbozos de la incipiente Política Social a los dictados de una Política Económica dispuesta a edificar un único mercado interior. Esta Política Económica tenía que admitir, no obstante, que la Política Social constituía un instrumento indispensable de la libre circulación de los trabajadores en la esfera de las comunidades que inicialmente fueron la CECA (Comunidad Europea del Carbón y del Acero), la CEE (Comunidad Económica Europea) y la CEEA (Comunidad Europea de Energía Atómica). El TP (Tratado de París de 18 de octubre de 1951) y los TTR (Tratados de Roma de 25 de marzo de 1957) dispersaron los gérmenes del Derecho Fundamental y los elementos primarios de una supuesta Constitución abierta que, aún hoy en día, no merece esa rotulación. A medida que aparecían los sucesivos textos comunitarios, nadie echaba de menos lo indispensable de una parte dogmática o enunciado de derechos innatos que acogiese inclusive los de corte social. Los desarrollos iniciales del Derecho Derivado se señalaron por la vulgaridad de las materias abordadas, la ausencia de connotaciones filosóficas y la parquedad de sus designios, allí donde las categorías capitales de 
la técnica jurídica reclamaban el espacio habitable y creativo que se les rehusaba. Comenzaba entonces la tarea de la construcción funcionalista o por agregación de la Europa que se pretendía levantar.

Así las cosas, la CECA se propuso mejorar el empleo y elevar el nivel de vida de los trabajadores en los Estados miembros, fomentar las reconversiones industriales, propiciar unos salarios justos y asegurar la libre circulación de mano de obra en los sectores del carbón y del acero. La CEE prometió ampliar las actividades económicas y mejorar el nivel de vida en la medida conducente a que, de modo automático, se alcanzase un progreso social fundado en el establecimiento de un mercado común y en la armonización progresiva de las legislaciones nacionales. Su texto acopiaba un conglomerado de normas sociales relativas al tránsito libre de trabajadores, la aproximación de las legislaciones nacionales, las disposiciones sociales, el FSE (Fondo Social Europeo) y el CES (Comité Económico y Social). La CEEA reconoció los derechos a la libre circulación y a la protección sanitaria de los trabajadores especializados.

Es el momento de examinar la suerte que los derechos sociales fundamentales de los trabajadores -objeto de una consideración secundaria- han corrido con vistas a su implantación cuasiconstitucional, después de soportar las parcas atenciones de una Política Social europea que debió hacer honor a su dignidad axiológica y despejar las animosidades que le han salido al paso.

La Política Social europea -relegada al papel de subproducto comunitario- difería de las Políticas Comunitarias vertebrales. Renunciando a uniformar las normas nacionales de Derecho Social, marcaba los criterios de coordinación que, al menguar las distancias entre las dosis de protección de cada Estado miembro, acercasen a la más generosa de estas. Gracias al dogma de irregresividad o interdicción de revocar las mejoras sociales conquistadas por los trabajadores, esos Estados se obligaban a no disminuir, cuando menos, y/o aumentar -mediante las acciones esperadas y exigidas- las variantes de tutela social confirmadas como derechos adquiridos. La noción de desarrollo sostenible arranca de esta idea, hoy vapuleada por los especialistas de la ceremonia de la confusión y el embuste que antaño alardearon de haberle atribuido un valor universal e inconmovible. Una ventaja que, mereciendo el asentimiento general, se ve asediada por la apetencia de los beneficios materiales o por las fuerzas -no tan mayores- que desatan las crisis económicas. Fruto también de la avidez irrefrenable con que, para desventura de buena parte de la humanidad, se comportan los incondicionales del neoliberalismo y los fanáticos del fenómeno globalizador.

La equiparación en el progreso -lema aparentemente audaz de la Política Social europea en el TCEE- no fue sincera por completo y, pese a lo cautivador de su enunciado, ha dependido siempre del economicismo sustancial de los proyectos emprendidos. La impropiamente llamada Política Social europea -acervo de las Políticas Sociales nacionales resueltas a elevar sus niveles de 
tutela- ha devenido el pariente pobre de las instituciones comunitarias. La obsesión economicista -que presupone la unificación monetaria anterior a la unidad política de Europa- no ha detenido, sin embargo, las tentativas de abrir un espacio social europeo para reactivar esas aspiraciones reprimidas.

Había, se quisiera o no, que situar el empleo en el centro de la Política Comunitaria, porque las estructuras de la Europa deseable reclamaban la cooperación -ontológicamente imprescindible y causalmente eficaz- del factor productivo en que estribaba la fuerza de trabajo. Era preciso evaluar la posibilidad y perspectivas de una Política de Empleo acorde con las realidades cognoscibles, proveer a la intervención de los interlocutores sociales, fomentar las iniciativas locales y dilucidar los problemas planteados por el acceso a las nuevas tecnologías y la gestión del tiempo de trabajo.

La Política Social también se enderezaba a mermar y/o distender la conflictividad de las relaciones industriales que -aunque henchida por el eco de la lucha de clases- entraba en vías de un aprendizaje civilizado y constructivo. No en vano, los sindicatos reconocían lo trasnochado de sus veleidades revolucionarias y comulgaban con las reglas de juego del Estado social y democrático de Derecho que, a raíz de la 2. ${ }^{a}$ Guerra Mundial, había ganado la partida. La práctica frecuente del diálogo social -que, ante acontecimientos recientes y un tanto familiares, hoy provoca reacciones estupefactas y sarcásticas- se consideraba el método adecuado para templar las confrontaciones radicales y afinar los mecanismos de información y consulta de los trabajadores, sobre todo en orden a las innovaciones tecnológicas y el funcionamiento de las empresas multinacionales.

También se anunciaba que -para mejorar la calidad de la cooperación y la coincidencia en los temas de protección social- convenía negociar con los interlocutores sociales un presupuesto europeo y suprimir las diferencias que, por razón de sexo, perduraban y debían eliminarse de inmediato.

El concepto de clase social se revisaba y entendía como la comunidad o comunidades formadas por las personas físicas que, sin perjuicio de su especialidad profesional y de las fuentes de sus recursos económicos, disponían de los mismos niveles de renta para colmar sus apetencias afines de consumo. Lo lúcido de esta distinción atenuaba los antagonismos entre los desheredados -expectantes de los cambios sociales que diesen fin a su estado de empobrecimiento- y los poseedores ufanos de riqueza que coartaban sus aspiraciones.

La justicia social y la mejora de la situación económica dependían del ejercicio responsable de las Políticas Comunes, en el espacio social europeo, y de los beneficios esperados de la cohesión económica y social.

\section{Individualización sociopolítica del 'espacio social europeo'}

El espacio social europeo -emplazado por la ideología innovadora en el solar cuya posesión reivindica- ofrece unos rasgos relativos a su coordinación, sus recursos y su significado o entraña cultural. 
Constituye un espacio armonizado por áreas y por objetivos, en lo mínimo, en lo máximo y en lo necesario, pues la unificación normativa es utópica y económicamente impracticable.

Equivale a un espacio de cohesión económica y social donde convergen los designios de igualación y desarrollo de los mercados de trabajo. La creación de los fondos estructurales tiende a reducir justamente las desigualdades, las acciones formativas refuerzan los nexos entre los sistemas de producción y educación, y la prosperidad de las relaciones individuales y colectivas de trabajo recaba un impecable esfuerzo de armonización.

Se trata de un espacio civilizado y poseedor de un patrimonio común, cuyo componente cultural reclama una tutela colectiva que el propio capitalismo predica de los sistemas productivos de los países industrializados con economía de mercado. Las categorías de la participación de los trabajadores y la negociación colectiva pertenecen a la esencia del espacio social europeo. La primera modera el ejercicio abusivo o desproporcionado de las potestades de organización en el gobierno de la empresa. La segunda genera un ordenamiento jurídico autónomo que el despliegue fecundo de las libertades sindicales instala en el ámbito territorial de la soberanía del Estado.

Se está ante un espacio comprometido con el diálogo que alivia las tensiones de la cohesión social y económica, propicia los contactos de los interlocutores sociales, interpreta auténticamente los episodios del cambio europeo y respalda las ventajas del acuerdo y la negociación.

Ante el paso cansino de los responsables del rescate de Europa, el AUE (Acta Única Europea de 17 y 28 de febrero de 1986) señaló los aspectos de una Política Social que, obedeciendo a la consigna de la igualación y/o armonización en el progreso, demostraba que la cohesión económica y social contribuía a disminuir las diferencias existentes entre las regiones y obstaba al retroceso de las menos favorecidas. Para refrescar la flaca memoria de los olvidadizos, se trajeron a capítulo el reconocimiento y recepción de los derechos sociales fundamentales de los trabajadores, cuya naturaleza de derechos subjetivos innatos -contemplados en la CSE (Carta Social Europea de 18 de octubre de 1951)- les inmunizaba frente a las presiones de la concurrencia y los actos de emulación competitiva.

Lejos de revelar una obstinación ciega en pro de la necesidad y utilidad de lo social, la oferta de un espacio social europeo se cargaba de razón al proclamar que, sin una cohesión social solvente y responsable, las perspectivas y promesas de establecer un gran mercado constituían una aventura irrealizable. La delimitación cabal de ese espacio requería enunciar exhaustivamente los derechos sociales básicos de los trabajadores, reconocer su derecho a la formación permanente y modernizar el régimen de las instituciones del Derecho Societario europeo.

Los sindicatos cooperaron a fijar las vías y niveles de la edificación del espacio social europeo. Mientras la legislación debía generar las normas capitales del Derecho Social comunitario, lo convencional abarcaría las 
innovaciones del diálogo social y las modalidades europeas de la negociación complementaria. Ello acaecería a los respectivos niveles, en los espacios comunitario propiamente dicho, nacionales, regionales y sectoriales. La agrupación eficiente de estos elementos -determinantes del crecimiento económico y la prosperidad del empleo- completaría la regularización tecnológica, la solidaridad de la protección social, la libre circulación de personas y el control democrático del mercado interior.

El pensamiento sindical europeo recordaba que, entre los antecedentes históricos del Derecho Social Comunitario, figuraba el depósito del Derecho de Gentes ocupado por el Derecho Social Internacional de la OIT (Organización Internacional del Trabajo) y la CSE, que acaba de citarse. Otro punto de referencia -insistentemente mencionado- fue la CCDSFT (Carta Comunitaria de Derechos Sociales Fundamentales de los Trabajadores de 8 y 9 de diciembre de 1989) que -impulsando la convergencia hacia los más altos niveles de protección social- prohibía supeditar la concurrencia económica del mercado único a la rebaja de las dosis de tutela que, según la ocurrente máxima del sindicalismo escandinavo «siempre más, nunca bastante», habían ganado firmeza.

Así pues, los derechos sociales fundamentales de los trabajadores, evocados con motivo de la promulgación del AUE y del examen de las estructuras del mercado interior, procedían de normas preinsertas en los instrumentos internacionales de la OIT, la ONU (Organización de Naciones Unidas), la OCDE (Organización para la Cooperación y el Desarrollo Económico) y el TCEE. Eran derechos subjetivos que, vislumbrados en el horizonte constitutivamente histórico de la razón práctica, merecían el reconocimiento y el respeto vinculados a la presunción del funcionamiento regular del mercado interior. Garantizaban la libre circulación de personas, el empleo y la retribución económica de la fuerza de trabajo, la mejora de las condiciones de vida y actividad profesional, la protección social, las libertades de asociación y negociación colectiva, la formación profesional, la igualdad de trato de hombres y mujeres, la información, participación y consulta de los trabajadores, la protección de la salud y la seguridad en el trabajo, la atención de los niños y los adolescentes, la cobertura de la tercera edad y el cuidado de las minusvalías.

\section{Predominio del 'carácter estrictamente armonizador y escasamente innovador' de la Política Social comunitaria}

El decisionismo de la Política Social comunitaria se inspiraba en los conceptos -coincidentes, afines o análogos- de cohesión, homogeneización, armonización, aproximación, colaboración y coordinación familiares al lenguaje de las nuevas instituciones europeas -que actuaban en el ejercicio de sus competencias- y de los actos cooperativos de los Estados miembros. 
La armonización de la Política Social mediante la igualación en el progreso figuraba en el TCEE y difería de la unificación o la uniformidad impuestas desde arriba a otras políticas de sus componentes. La unificación asignaría las competencias sobre Política Social a un órgano comunitario investido de la potestad normativa oportunamente adjudicada. La uniformidad obligaría a cada Estado miembro a adoptar y aplicar criterios sensiblemente iguales para ordenar esa materia. La armonización -pensada para equiparar las condiciones de vida y de trabajo- atenuaría los inconvenientes derivados de un funcionamiento excesiva o abusivamente liberal del mercado. Se echaría mano, a tal efecto, de los arbitrios reductores que el Derecho Fundamental comunitario inventase -esto es, idease de acuerdo con la recta razón - para coordinar el Derecho Social objetivo de los Estados miembros.

Como lo mejor suele ser enemigo de lo bueno, se explica que la labor -utópicamente anhelada y económicamente inviable- de unificar o uniformar las normas jurídicas rectoras de la Política Social europea cediese su lugar a la, más comedida y accesible, de coordinar, aproximar o aminorar las distancias existentes entre las soluciones nacionales. Ello, al amparo de los principios centrales que, como mínimos de Derecho necesario, prohibían las discriminaciones por razón de sexo e inspiraban los derechos de acceso al empleo, determinación de las condiciones de trabajo y formación profesional.

Los augurios de esta tibia Política Social no electrizaron a los arquitectos de un sistema resuelto solamente a instalar un único mercado interior $\mathrm{y}$ auscultar las probabilidades de la unidad política de Europa. No por ello quedó en suspenso el empeño de ir en pos de los objetivos sociales, aunque el proceso constructivo de este sector del ordenamiento jurídico comunitario registrase variaciones - de velocidad y de ritmo- que, unas veces, respondían a la buena conciencia de los eurocreyentes y, otras, al recelo de los euroescépticos y/o la enemistad de los adversarios.

La grandeza y servidumbre del espacio social europeo dependían de la irrupción comunitaria de los derechos sociales fundamentales de los trabajadores, cuya efectividad removería, para siempre, las dificultades opuestas por la mezquindad de las técnicas armonizadoras. Su existencia indudable y sus predilecciones expansivas encarecían la práctica del diálogo social que, recorrido por la savia de la solidaridad y la flexibilidad razonable, impulsaría el avance científico y la efectividad transformadora del naciente Derecho Social europeo.

\section{Proliferación de los esfuerzos transformadores de adelanto y acceso a 'la tierra prometida de la Europa Social'}

La credibilidad de la apuesta del optimismo liberal decayó al comprobarse que -en contra de las predicciones de la doctrina del orden natural- la armonización de la Política Social europea nunca derivaría del supuesto 
automatismo atribuido al regular funcionamiento del mercado interior. Dicho convencimiento provocó las tareas de acomodación consistentes en elaborar programas sobre actividades sociales, de los que fueron ejemplos emblemáticos la regulación de la acción social comunitaria a medio plazo y la conversión del FSE en un instrumento de política activa. Con motivo de estos ensayos correctores, la línea de fuerza filosófica del AUE reiteraba la urgencia de combatir la desocupación, mejorar la participación de los interlocutores sociales y acelerar el desarrollo de la Política Social. Los textos complementarios que estudiaron la dimensión social del mercado interior defendieron la prioridad de la lucha contra el desempleo, divulgaron las normas de acción pertinentes, esclarecieron el papel de los fondos estructurales respecto a la cohesión social y económica, y reiteraron el elogio de las excelencias del diálogo social.

Se hizo hincapié en la urgencia de adjudicar fuerza normativa a la CCDSFT -yacimiento de la lista de los derechos sociales fundamentales de los trabajadores- que, a la luz de los imperativos del mercado interior, formaba parte del acervo de la cultura europea y del depósito de las normas del Derecho Internacional Público. Ante los reparos opuestos a dotar a esos textos de eficacia preceptiva directa, se invitó a presentar iniciativas que asegurasen su efectividad y encauzasen sus aptitudes de transformación.

Las más importantes fijaron los criterios que informaban tal invitación. Un principio de subsidiariedad, que asignase a cada objeto de las actividades la función más consecuente con las necesidades atendibles y la totalidad del esfuerzo comunitario. Un principio de diversidad de sistemas, culturas y prácticas nacionales, que promoviese el perfeccionamiento del mercado interior. Un principio de competitividad de las empresas, que, evitando las distorsiones de la competencia, proveyese a la cohesión económica y social. La intervención de los agentes sociales coadyuvaría al buen fin del proceso que, una vez iniciado, no admitía paralizaciones ni rebajas.

El tema central de los derechos sociales fundamentales de los trabajadores quedó aparcado durante algún tiempo. El esbozo atípico de una incompleta Constitución europea se había limitado a encadenar los sucesivos textos que, además de incurrir en la conocida paradoja del Derecho Comunitario, prescindían de la parte dogmática que era la sede natural de aquellos. La suerte de su recepción y desarrollo se mostraba confusa y desalentadora.

\section{Emergencia y perfil fisonómico de la Unión Europea}

Al TUE (Tratado constitutivo de la Unión Europea de 9 de febrero de 1992) -conocido con el nombre de Tratado de Maastricht- se llegó cuando los desenvolvimientos del AUE convencieron de que el nivel de tutela de los valores sociales de la Comunidad era notoriamente inferior al de sus presupuestos y condiciones economicistas. Las resonancias de la mala conciencia europeista exigían crear un espacio sin fronteras internas y revigorizar los 
ingredientes de la cohesión social, para promover el progreso comunitario colectivo, fomentar un elevado nivel de empleo y asegurar un desarrollo equilibrado y sostenible. Objetivos a los que se sumaron la constitución del FSE y el compromiso de implantar una enseñanza y formación de calidad.

La UE (Unión Europea) que así se constituye deja de constreñirse exclusivamente a lo económico y acoge los objetivos difuminados hasta entonces. La Política Social pierde el carácter de subproducto comunitario y ofrece un inventario de finalidades que aseguran la igualdad material de hombres y mujeres en el mercado de trabajo, integran a las personas excluidas de las relaciones de empleo, establecen la seguridad y la protección sociales, combaten las extinciones injustas de los contratos de trabajo, disponen mecanismos de representación y defensa colectivas que incluyen la cogestión, mejoran las condiciones de trabajo de los nacionales no comunitarios y proveen a la creación y el crecimiento del empleo. La Política Social de la UE no aborda el régimen retributivo ni las libertades sindicales y sus derivaciones, confiando en que los sindicatos -interlocutores sociales caracterizados- faciliten un modelo de negociación colectiva conforme a las particularidades y exigencias del ámbito europeo en que ha de operar su autonomía.

La nueva Política Social incorpora el principio de subsidiariedad, pues la Comunidad -que deja de concebirse como exclusivamente económica y, al suprimirse este adjetivo, pasa también a ser social-apoyará y complementará las acciones de los países miembros. La estructura de la UE añade a los pilares integrador, cooperativo y unitario, un pilar de reducción que, mejorando el gradualismo de las técnicas de la construcción europea, reemplaza la modestia coordinadora de las Políticas Sociales nacionales por la fertilidad creativa que se espera de la Política Social comunitaria.

El sindicalismo de izquierdas había denunciado las aspiraciones de consolidación capitalista del mercado común interior y su inutilidad para transformar equitativamente las relaciones individuales y colectivas de trabajo. Con el cambio de rumbo debido al nacimiento de la UE, las organizaciones sindicales insinuaron la oportunidad de que las izquierdas europeas se asociasen a las operaciones de lanzamiento de la Política Social, reclamaron el protagonismo de las organizaciones obreras -desligadas de sus mitos revolucionarios- en las nuevas funciones de los Estados miembros y apuntaron la eventualidad de que la Europa Unida formase un bloque sindical frente al gigante americano y en pro de la apertura a los países del Este. Sin perjuicio de plantearse, además, la alternativa entre un modelo sindical de seguridad conservadora y otro de responsabilidad innovadora.

La apatía ratificadora se debió a que el TUE fijaba los criterios de tránsito a la fase de Unión Económica y Monetaria -a saber, las magnitudes de la inflación, el déficit público, la deuda pública, el tipo de interés y la estabilidad de los tipos de cambio- y guardaba silencio sobre la recepción de lo social. Un repertorio plagado de intenciones óptimas descuidaba el objetivo 
de igualación en el progreso e incurría en una inconsecuencia de bulto. El defecto se salvó gracias a que la posterior regulación del TA (Tratado de Ámsterdam de 2 de octubre de 1997) -modificativo del TUE- abordó significativamente el tema del Empleo.

El contenido adicional o periférico del TUE únicamente invitaba a los Estados miembros a continuar la vía de la CCDSFT, del que los socios insulares se habían apartado, y expresaba el deseo, pero no la ineludible determinación, de aplicar dicho texto a partir del acervo comunitario que encerraba el ordenamiento jurídico inmanente a la naturaleza de las instituciones europeas. Las disposiciones concernientes a la Política Social, la Política Educativa y la Política de Formación Profesional completaron, por obra y gracia del TUE, la apertura expansiva de este panorama normativo.

\section{Aclaración de las opacidades y otros inconvenientes del 'laberinto normativo comunitario'}

El TA introdujo un cuadro de reformas idóneas para iluminar el laberinto normativo derivado de un estado de cosas en que la estructura formal interna de los textos comunitarios se parecía más a una ocurrencia surrealista novelada que a un texto cuasiconstitucional donde la parte dogmática -sede de los derechos sociales fundamentales de los trabajadores- brillaba por su ausencia. Su estructura -irregular y sorprendente- llegó a compararse con la disposición arquitectónica de un templo griego compuesto del frontispicio de las disposiciones comunes, de tres o cuatro pilares sustanciales y del basamento en que descansaba su totalidad.

El contenido adicional o periférico del TA dejó sin efecto la parte homóloga o simétrica de las adiciones al TUE, donde anidaban los óptimos propósitos que el TCE elevaría después a normas jurídicas. Pese a esta parcial sicosis de arrepentimiento, decayeron la oferta de la parte dogmática constitucional y la lista completa de los derechos sociales fundamentales de los trabajadores que tantas y tan justificadas ilusiones habían despertado. La intencionalidad que, en pro de dicho reconocimiento, refleja el prefacio del TUE, anticipa la vehemencia y el énfasis con que la introducción al TA proclamaría textualmente la adhesión a los principios y valores acogidos por la CSE y la CCDSFT.

El TA aportó precisiones notables sobre la consigna originaria de la equiparación social a través de la igualación en el progreso. Se impuso a la UE y a los Estados miembros el deber positivo y no la promesa nebulosa de aunar los esfuerzos tendentes a perfeccionar una protección social adecua$d a$. Algo más apremiante y retador que una cobertura pensada para salir del atolladero o atenuar el mordiente de ciertas insistencias. Se realzó la premura de que las acciones de exploración y vigilancia-confiadas a los experimentos nacionales- supervisasen el cumplimiento de esa acumulación de obligaciones. Aunque la Política Social siguió incumbiendo, en la parte que 
les correspondía, a cada uno de los Estados miembros, el Empleo -que, salvando anteriores y censurables omisiones, merecerá un alojamiento decisivamente innovador- se elevó a la condición de materia de interés común y se introdujo un trámite de codecisión para promover y dar curso a las iniciativas nacionales.

El TA dignificó la Política Social y evidenció el propósito de servir a las exigencias del progreso, pero, debido a las disidencias sempiternas, desatendió -como se ha repetido- las advertencias relativas a la recepción y tipificación comunitarias de la tabla de los derechos sociales fundamentales de los trabajadores y se abstuvo de poner en negro sobre blanco los compromisos de liquidar las injusticias colectivas, combatir la discriminación y la pobreza, y reprimir las exclusiones sociales.

Pese a la enjundia de estas deficiencias, la elevación del empleo a la categoría de objetivo comunitario preconizaba un espectacular giro social, censuraba la ligereza con que sus detractores le adjudicaban el mote de espejismo, y comulgaba con las propuestas del Estado de Bienestar. He aquí uno más de los puntos de encuentro entre el oscuro objeto del deseo y la meridiana percepción de lo factible. La acertada elección del modelo de la Europa deseable dependía de conciliar, inteligente e intuitivamente, las actitudes que sintetizasen los irrenunciables arrestos de los valores morales y las posturas dúctiles de las contemporizaciones políticas. Significaba lo contrario de la pasividad estática con que se contemplaba ese futuro como una dádiva u obsequio que, graciosamente llovido del cielo, eximía a los eurocreyentes de continuar las tareas de su recreación y mejora.

\section{Irrupción intensiva del tema de los 'derechos sociales fundamentales de los trabajadores'}

Desde la racionalización técnico-jurídica de las premisas del Estado demoliberal, los derechos fundamentales ocuparon los compartimentos que los constituyentes destinaban a proclamar su cualidad de derechos naturales, inherentes a la existencia y duración de la persona humana, que los ejercitaba, y anteriores a un Derecho Positivo subordinado a sus valores y/o principios. Se hace de estos derechos tabla rasa cuando la fuerza mayor de los acontecimientos históricos o la obnubilación de los entendimientos de los hombres entorpecen las operaciones dirigidas a fijar su contenido esencial y sus perfiles.

El silencio de los textos europeos daba a entender que, al faltar una aseada catalogación de esos derechos, la Constitución material comunitaria era incompleta. No faltaba razón a cuantos, entendiéndolo así, mantenían su postura de reprobación. La doctrina judicial complementaria aportó el remedio de una formulación provisional y persuasiva. Si los derechos fundamentales nacionales gozaban de una tradición, histórica y jurídica, común a todos los Estados miembros, su enclave en las respectivas parcelas constituciona- 
les les deparaba una tutela permanente contra las vulneraciones causadas por cualesquiera normas o resoluciones emanadas de los poderes públicos comunitarios.

Dos órdenes de motivaciones daban lugar a este retraso antisocial. Una era la tibieza calculada del decisionismo político, refractario al cambio sustancial -revolucionario desde el interior-que importaba la irrupción de los derechos sociales fundamentales de los trabajadores. La otra venía del voluntarismo económico que, obviando los aspectos moralizadores e intelectualistas del problema, relegaba la Política Social a un plano secundario y prefería no enterarse de sus más acuciantes llamamientos. La demora ocasionaba perjuicios enormes, porque la recepción comunitaria de los derechos sociales -pertenecientes a la parte dogmática constitucional sumergida- impulsaba los cambios inspirados en la idea de que la efectividad esperada de la atribución y el ejercicio de tales derechos, no solo se hallaba en su aptitud para pacificar las controversias entre partes, sino también en su irrefrenable propensión a transformar la sociedad. Una consigna que el art. 3 II CI (Constitución italiana de 29 de diciembre de 1947) tomó a préstamo del pensamiento jurídico soviético y que pasó atenuadamente al art. 9.2 CE (Constitución española de 27 de diciembre de 1978) e incluso al art. 4.3 EAPV (Estatuto de Autonomía de País Vasco de 20 de octubre de 1979).

Es, con todo, axiomático que la naturaleza de las cosas imponía -como tales derechos en la esfera comunitaria- la libre circulación de trabajadores y las libertades de establecimiento empresarial y circulación de capitales.

El TCEE diseñó los rasgos distintivos de una Política Social cuyo lema central de igualación en el progreso atisbaba, sin mucho entusiasmo, el panorama del espacio social europeo. Faltaba la positivización de un Derecho de Gentes protector de los intereses sociales que, una vez vestidos y provistos de la efectiva tutela judicial que los robustecía, completasen una parcela capital de la esperada Constitución para Europa. El hueco abierto no se acababa de colmar y la ejecución de la faena se estancaba indefinidamente.

\section{Estado de cosas anterior al Proyecto de Tratado por el que se estable- ce una Constitución para Europa}

El contenido adicional del TUE introdujo simplificaciones que no bastaron para disipar las incertidumbres ni llenar los vacíos que acusaba el TA. La DFUE (Declaración de Laeken de 12 de diciembre de 2002 sobre el futuro de la Unión Europea) usó, por vez primera, el término Constitución y dedicó uno de sus apartados al Camino hacia una Constitución para los ciudadanos. La jurisdicción comunitaria evitaba mencionar nominativamente la Constitución y empleaba, en su lugar, otros vocablos genéricos o afines. Aunque el TN (Tratado de Niza de 7 de diciembre de 2000, sin carácter constitucional) había aprobado la CDFUE (Carta de Derechos Fundamentales de la Unión Europea, que ha prevalecido con las precisiones de 12 de diciem- 
bre de 2007) y purgado la mala conciencia que sus aplazamientos despertaban, perduraba un clima de desentendimiento que alargaba excesivamente la factura del trabajo constitucional. Al cabo de los numerosos y consabidos desencuentros, el ritmo mínimo de normalidad se recobró merced a las contribuciones del PCE (Proyecto de Convención Europea de 18 de julio de 2003) y el PCI (Proyecto de la Conferencia Intergubernamental de 18 de junio de 2004) que, obligando a un decoroso consenso, permitieron suscribir el PTCUE (Proyecto de Tratado de 29 de octubre de 2004, por el que se establece una Constitución para Europa). También se le llamó TC (Tratado Constitucional) para expresar la contradicción en los términos que, aquejando a su génesis y contenido, impedía considerar Constitución, en sentido técnico-jurídico, a la propuesta dependiente de la ratificación de los Estados miembros. La paradoja del Derecho Comunitario subyacía al tracto y la desembocadura de este pensamiento.

La continuidad del desarrollo sostenible era uno de los soportes que, según el PTCUE, sustentaba la viabilidad de los derechos sociales fundamentales de los trabajadores. Su noción, familiar al lenguaje europeísta, se elevaba a condición irrenunciable de la redefinición y ejecución de la Política Social comunitaria. El desarrollo sostenible representaba la versión modernizante de la paz que, reviviendo el vejado principio de irregresividad de las adquisiciones sociales, informaría de la siguiente proposición antropocéntrica. Si no se consolidan la conciencia de la necesidad de vivir dignamente y la voluntad de responder, corriendo riesgos, a los retos de la cosmoeminencia personal, fracasarán cuantos esfuerzos desplieguen los individuos y los grupos sociales para satisfacer sus más caras y justas ilusiones de liberación.

La tesis del desarrollo sostenible condena la tosquedad moral y la miseria intelectual de quienes opinan que, pasadas de moda las oportunidades de auxiliar a los pobres que pueblan la superficie de la Tierra, ha llegado el momento de sustituir esa defensa por la de causas más lucrativas y excitantes. La economía social del mercado -inseparable de la especulación y el pragmatismo del desarrollo sostenible- postula una Política Social que, al descartar las fórmulas de la coordinación y el gradualismo insincero, coloca los derechos sociales naturales o innatos en vanguardia de sus aspiraciones. El desarrollo se dice sostenible, porque los fiadores de su irreversibilidad admiten la existencia de recursos bastantes para respaldar la continuidad de los compromisos contraídos, conjurar los peligros de sus regresiones desproporcionadas e impedir las paralizaciones que hieren de muerte su supervivencia. Lo cual, a estas alturas de los tiempos, no ha resultado ser cierto del todo.

Nada de ello podía pretenderse sin que, en el espacio social de la UE, compareciesen -demostrando la disponibilidad en pie de guerra que procuran los derechos procesales de acción y de excepción- los derechos fundamentales de ese signo, divisados en el horizonte constitutivamente histórico 
de la razón práctica que obligaba a reconocerlos constitucionalmente y a concretar su contenido esencial o núcleo invulnerable.

El ejercicio fructífero y frecuente de los derechos sociales europeos -anejos a las ambiciones del desarrollo sostenible - produciría valiosas consecuencias. A saber, la coexistencia pacífica de las comunidades y/o los grupos sociales, la distensión del antagonismo de las confrontaciones, la lucha contra los conflictos erosivos de la solidaridad y la prosperidad, y la coordinación de la vida en dignidad de las personas físicas. El TN se había apresurado, para ganar tiempo, a sancionar la CDFUE como pieza prefabricada del orden constitucional que se preparaba para Europa. El PTCUE recogió dicho texto, incorporando los derechos nuevos, que recibían el bautismo de fuego constitucional comunitario, y los que, ya reconocidos, se aprovechaban de una tutela reforzada por los avances del progreso social y las contribuciones de la tecnología y de la ciencia.

Bajo la rúbrica genérica de Solidaridad, la CDFUE -cuyas vicisitudes ya constan- brindaba la lista de los derechos sociales fundamentales de los trabajadores que comprendía la información y consulta de sus representantes en la empresa, la acción sindical y la negociación colectiva, el acceso a los servicios de colocación, las garantías en los casos de despido injusto, el establecimiento de condiciones equitativas de trabajo, la protección del trabajo infantil y juvenil, la cobertura social de la familia y el régimen público de la Seguridad Social. La irrupción tardía de tales derechos en el sector social del ordenamiento jurídico comunitario premiaba, conforme a la fuerza de las cosas, la tenacidad de las reivindicaciones incoadas, mucho tiempo atrás, por las insistentes y genuinas demandas sociales.

El fracaso de la ratificación unánime del PTCUE dio al traste con la tentativa técnico-jurídica de disolver la paradoja del Derecho Comunitario y culminar los pasos sucesivos que la estrategia funcionalista proponía para obtener un resultado final satisfactorio. A saber, organizar una Europa social coherente y no diseminada en parcelas heterogéneas y asimétricas, consolidar el arraigo de los titulares de un verdadero poder constituyente europeo y redoblar las energías para ofrecer a los ciudadanos comunitarios las dosis de bienestar que implicaba la penetración de los derechos sociales fundamentales de los trabajadores en el marco de una genuina Política Social y no de un sucedáneo de esta.

Quedó fuera de juego la concepción constitucionalista partidaria de erigir de inmediato una organización europea de corte federal. La estrategia funcionalista -que ha prevalecido- defendía que Europa no se levantaría de una vez, por obra y gracia de una construcción repentina y global, sino de sucesivas acciones respaldadas por un recio sentimiento de solidaridad y asociadas al novísimo concepto de soberanía divisible. La recepción de los derechos sociales fundamentales de los trabajadores ha sido fruto de una metodología existencial que pasa por alto las invocaciones de su estirpe yusnaturalista y de su condición originaria. 
Las averiguaciones estadísticas demostraron que el fracaso de la ratificación del PTCUE no solo procedía de la enemiga de los disidentes de los objetivos centrales de la integración europea. Tras las explicaciones de un estropicio tan visible, se agazapaba el desencanto de quienes confiaron en renegociar un texto más social y obediente a la idea de que habría merecido la pena poner manos a la obra de regenerar y construir una Europa distinta. La suerte de la soberanía de los Estados miembros de la UE -expuesta a percepciones de intensidad variable - no quedaba al margen de las razones del repudio. Ni la propaganda gubernamental, ni la pedagogía de la oposición parlamentaria, ni las organizaciones sindicales del Reino de España, ni los medios de comunicación transmitieron a la opinión pública la información que -veraz, detallada y comprensiblemente- aclarase la supuesta excelencia de un futuro constitucional-receptor de los derechos sociales fundamentales de los trabajadores- que naufragó antes de que se hiciese a la mar su embarcación.

\section{Circunstancias que acompañan a la preparación y perfección del Tratado de Lisboa}

Tras la ratificación efectuada por 18 de los Estados miembros de la UE, el rechazo de dos de ellos y la posposición definitiva de aquella por parte de los siete restantes, fracasó la huida hacia adelante del PTCUE o TC y, a lo largo de un trienio convulsivo y confuso, se enfrentaron las preferencias y propuestas que afluyeron a la firma del TL (Tratado de Lisboa de 13 de diciembre de 2007). Su texto -que modificaba y no derogaba el TUE y el TCE- reemplazó la rotulación del segundo por la de TFUE (Tratado de Funcionamiento de la Unión Europea).

Una de sus bondades destacables consistía en atribuir naturaleza legalmente vinculante a la tan repetida CDFUE, aprobada anteriormente por el $\mathrm{TN}$. Conviene recordar que -con la más lúcida y sincera de las intencionesel proemio del TA había añadido al del TUE una proposición introductoria que enriquecía y aclaraba decisivamente la filosofía de aquel prólogo. Confirmaba que los Estados miembros de la UE prestaban su adhesión al elenco de los derechos sociales fundamentales, tal y como la CSE y la CCDSFT -continentes primarios e insustituibles del depósito del Derecho Social Europeo- los definieron a su tiempo. El yusnaturalismo idealista -de filiación aristotélico-tomista- y el yusnaturalismo realista -de corte secularsustentaban, a través de ambos textos, los merecimientos axiológicos de una Política Social que se estimaba inmejorable.

Según el TL, la UE reconoce los derechos, libertades y principios enunciados en la CDFUE ya citada -a la que se remite en bloque, sin reproducir su contenido- y le asigna el valor jurídico de uno más de los Tratados. Advierte que el refuerzo de la protección de los derechos fundamentales de la UE -de que los derechos sociales de los trabajadores forman parte- se 
debe a las transformaciones de la sociedad, a los imperativos del progreso social y a los avances de la tecnología y de la ciencia. Cuida de subrayar que las libertades anejas a la circulación de personas y prestación de servicios en la esfera comunitaria solo devienen reales y efectivas si les acompaña un desarrollo equilibrado y sostenible. Cabe, hoy en día, preguntarse por el futuro de este haz de derechos en las espeluznantes circunstancias -de recesión o de crisis- que remueven las premisas históricas de su recepción y garantía.

He aquí el inventario que -gracias a la remisión global del TL- hace la CDFUE de los derechos sociales en función de los conceptos generales de Dignidad, Libertades, Igualdad, Solidaridad y Justicia.

Bajo la rúbrica de Dignidad, figuran la protección de esta cualidad inviolable, el derecho a la vida y la integridad física, y las prohibiciones de la esclavitud o servidumbre, de la ejecución de trabajos forzosos y del comercio de seres humanos en las relaciones de trabajo.

El grupo de las Libertades abarca el reconocimiento del derecho a la libertad y seguridad de los trabajadores en cuanto ciudadanos, las libertades de pensamiento, conciencia y religión, opinión, información sin trabas, reunión, fundación y afiliación a sindicatos en defensa de sus intereses, acceso a la formación profesional y permanente, trabajo y ejercicio de una profesión libremente elegida y aceptada, demanda de ocupación en el mercado de empleo y prestación de servicios en cualquiera de los Estados miembros.

Por modo de Igualdad, se proclama el principio general de igualdad material y se vedan las discriminaciones en las relaciones de trabajo, se garantiza el pluralismo cultural, religioso y lingüístico de los trabajadores, se reitera la igualdad de hombres y mujeres respecto al empleo, el trabajo y su retribución, y se reconoce el derecho de las personas discapacitadas a beneficiarse de las medidas protectoras de su integración profesional.

$\mathrm{Al}$ amparo de la Solidaridad, se recogen la información y consulta de los trabajadores en la empresa, la negociación y las acciones colectivas, incluida la huelga en defensa los intereses afectados, el acceso a los servicios de colocación, la protección contra los despidos injustificados, la fijación de condiciones de trabajo adecuadas a la salud, la seguridad y la dignidad de las personas, el tiempo de ocio y de descanso, la prohibición del trabajo infantil, el amparo de los trabajadores jóvenes frente a la explotación económica o las especies de trabajo peligrosas para su desarrollo, su educación y su salud, amén de la armonización de la vida profesional y familiar, el acceso a los beneficios de los regímenes públicos de Seguridad Social y la lucha contra la exclusión social y la pobreza.

Bajo el encabezamiento nominativo de Justicia, los derechos sociales fundamentales de los trabajadores obtienen la efectiva tutela judicial que, evitando la indefensión de las partes que actúan sus pretensiones respectivas, garantiza el examen de las vulneraciones de aquellos y la emisión, a cargo de la jurisdicción competente, de una respuesta -formalmente motivada y 
suficientemente fundada en Derecho- a las cuestiones sustantivas que se han planteado en el proceso.

\section{1. ¿'Futuro postlisboeta indefinido’ de la UE respecto a los derechos fundamentales de los trabajadores?}

Las tensiones causadas por el fatigoso reconocimiento de los derechos sociales fundamentales de los trabajadores seguirán informando de la querencia a la nacionalización residual que opone el particularismo de los ordenamientos jurídicos de los Estados miembros al talante generalizador del Derecho objetivo de la UE. Ello, no obstante la autoridad y la impronta de la primacía y el efecto directo del Derecho Comunitario. Prueba de que no se apuesta resueltamente por la integración y de que las posiciones de resistencia blanda ocultan un cajón de sastre donde cohabitan discrepancias irreconciliables.

Los jueces del orden social, como los de las demás jurisdicciones, no apuran los esfuerzos tendentes a seleccionar, si es del caso, la norma del ordenamiento jurídico de la UE que debe aplicarse. Prescinden de estas averiguaciones y acostumbran a situarse en el marco del sistema de fuentes

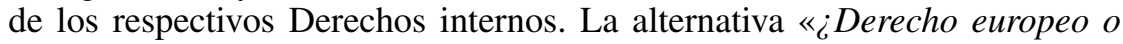
Derechos nacionales?» encierra un aspecto de curiosidad doctrinal avalada por las estadísticas judiciales y el interés de los estudios a que ha dado lugar. Ni el porvenir de este debate está prejuzgado, ni se cuenta con una metodología irreprochable para enfocar su porvenir. Hay excepciones, si se trata de normas comunitarias notorias que agrandan el elemento histórico de la causa de pedir - identificadora de la acción ejercitada- y que deben ingresar de oficio en el debate. Cabe asimismo que las partes aleguen principios o preceptos de Derecho Social europeo que, ante los caracteres del problema pendiente de resolución, lleven al planteamiento de una cuestión prejudicial. Los episodios de nacionalización residual o de horror al vacio se aprecian también cuando los legisladores estatales aplazan o descuidan el desarrollo tempestivo de las Directivas en materia de Derecho Social europeo. Las ambigüedades y evasivas abundan frente a lo amable y sugestivo de la finalidad integradora. La jurisdicción se siente desarmada si no se dan las condiciones que, para suplir la mora legislativa, le permiten aplicar directamente la norma comunitaria pendiente de transposición.

La Política Social -antes comunitaria y hoy día de la UE- y el Derecho propio de sus requerimientos no pueden esperarlo todo del ejercicio del poder de codecisión conferido al CUE (Consejo de la Unión Europea) y el PUE (Parlamento de la Unión Europea) para la producción ordinaria de normas jurídicas. Cualquier hipótesis que surja en este punto obliga a un discurso denso y responsable sobre cuestiones tan sensibles como eludidas o tratadas superficialmente. A saber, la falta de un espacio público europeo, la diversidad de las estructuras sindicales, la inexistencia de partidos políticos 
transnacionales, las limitaciones impuestas al control de la CUE por el PUE y la sustracción a este último de competencias naturales. Carencias lesivas para una Política Social que ha sido la última en beneficiarse de las rectificaciones del economicismo antiguo del diseño europeo y que, aun dejando de constituir un subproducto comunitario, prosigue expuesta al virus de las contaminaciones globalizadoras.

Las cosas pueden ocurrir de otro modo, si el porvenir postlisboeta de la UE se escribe derecho con renglones torcidos y se enmiendan algunas de sus deficiencias. La empresa consuntiva que ha supuesto la recepción de los derechos sociales fundamentales de los trabajadores en el espacio de la UE enseña que -superando la tibieza interpuesta entre la hostilidad y el entusiasmo- ahí palpita una de las divergencias capitales que afectan a los Estados miembros de la UE e incluso a sus pueblos respectivos. Se han discutido hasta la extenuación, sin cerrar acuerdos provechosos, las cuestiones polémicas que miran al concepto inequívoco de lo que significa la integración europea, a los elementos que preferiblemente han de elegirse para delimitarla con exactitud términológica, a la concreción de los intereses y bienes jurídicos que subyacen a los enunciados ampulosos y vastos, y a las estrategias idóneas para liquidar los obstáculos y las desavenencias. Los desencuentros conceptuales ocultan, si se llega al fondo de las cosas, diferencias culturales e imperativos económicos harto costosos de reconciliar. La redacción de los textos abunda en reiteraciones consensuadas o divergencias gramaticales que confirman la imposibilidad de plasmarlos, a gusto de todos, en el correspondiente idioma nacional. He aquí una de las intransigencias que vician el proceso en examen y endurecen la flexibilidad de su progreso. Con razón, llevan el nombre de compromisos apócrifos las fórmulas que, pretendiendo integrar pacíficamente un cúmulo de exigencias contradictorias, las mantienen vivas y embrollan la polémica en torno a las cuestiones que dicen haber dilucidado.

Una parte de los ciudadanos europeos -atentos al dictamen del sentido común- no ha desistido de culminar su ensoñación unitaria, porque la lógica de los acontecimientos coetáneos les disuade de aceptar, con buena dosis de resignación, el triunfo de las inconsecuencias que la empañan. Hay una paradoja más entre las apreciables. La maleabilidad expansiva del mundo globalizado otorga a todos los pueblos de la Tierra unas facilidades que, pese a los alejamientos geográficos, se aprovechan para concertar, con avidez y sin recelos, ilusionadas aventuras de amplio espectro. Diligencia y solicitud que se echan de menos en los episodios protagonizados por el módico número de actores que, entre si tan cercanos, comparten los esfuerzos de edificar Europa.

Reparos desalentadores y debidos a la intolerancia con que ciertos Estados miembros se escudan en la figura proteica de un Superestado-que predica una Europa sin alma- y, atrapados por esta prestidigitación, cierran filas a la hora de dar el paso a la unión política. No están resueltos a ceder 
y/compartir soberanías y poderes, identidades y lealtades, porque su voluntad irrevocable ha sido y sigue siendo la de no ir más allá del establecimiento de un mercado común que clausura el capítulo de sus pretensiones sobre la perfección europeísta. Sus posturas erosionan la causa de los derechos sociales fundamentales de los trabajadores en el espacio de una Europa uni$d a$, si se quiere, pero inferior cualitativamente a la causa de otra Europa posible -la tierra prometida de la Europa social-que proponían los defensores de una integración moralizadora y solidaria. Algo inviable, si los Estados miembros no ceden unánimemente una parte sustancial de su soberanía divisible al emergente pueblo europeo -pendiente de estrenarse como nuevo sujeto originario o en raíz de esta- y a las instituciones que la imaginación de la UE ha de crear para garantizar formas honorables de representación popular y ocupar el espacio público en que se materialice la opción federativa.

El pueblo europeo, compacto y coaceptado como tal, está legitimado activamente para reclamar -con la coherencia de lo razonable- orden, concierto y simplificación allí donde, junto a una dosis vitanda de complejidad, laten las confrontaciones que enturbian la imagen deseable de una UE en que, según un acreditado principio dinámico, el Derecho Fundamental y el Derecho Derivado resulten irreprochables, los mecanismos de su actuación sean irresistibles y la jurisdicción se ejerza irreprehensiblemente. La voluntad constituyente de ese pueblo ha de adjudicar a la sociedad europea un sistema de seguridad jurídica compatible con las acciones y/o reacciones elásticas que, sin esterilizar la creatividad ni vulnerar la naturaleza de las cosas, hayan de agilizarse en cada tiempo. Únicamente el pueblo europeo -firmemente asentado en un espacio público común- puede hacer gala de una identidad y una lealtad tan iguales a sí mismas como coexistentes con el pluralismo social y las diferencias individuales que lo caracterizan. Habrá cuajado entonces la demanda social europea que han de atender las instituciones competentes, cancelando las discrepancias que oscilan entre las objeciones rituales - de parco fundamento- y las concesiones y/o protestas domésticas de escasa cortesía.

La Política Social europea puede beneficiarse, en trances normales y no en circunstancias de excepción, de la modernidad de un Derecho Social construido gracias a la voluntad originaria o en raíz de un verdadero pueblo soberano, a imagen y semejanza de los procesos constituyentes dignos de llevar este nombre. No de las ficciones o artificios que lo han suplantado en virtud de un sistema de fuerzas corregible a través de las oportunidades que ofrece el TL. Instrumento que sitúa en las vísperas - ¿interminables o de muy larga duración?- de la solución definitiva que supone una Constitución para Europa. Una carta política de corte federal, purgada de los inconvenientes que, hasta el momento, impiden definirla como la síntesis de las experiencias del pasado y de la vida nueva que sus enseñanzas aconsejan. 
La UE ha reaccionado, aquí y ahora, frente a las sorpresas de la economía general de los Estados miembros, como el sujeto activo de una parte de la soberanía divisible de naturaleza económica. La asume y ejercita en el proceso globalizado de combate contra el género de la recesión y las especies críticas en que se plasma este fenómeno. Junto a las recomendaciones coercitivas que afectan a los Estados miembros de la UE, el G-20 -agrupación de las economías de mercado consolidadas o emergentes- se atribuye un control horizontal, también soberano de hecho, sobre la Política Económica de los países que disponen de un plazo perentorio para normalizar su endeudamiento a través de una rebaja insoslayable. Entra en circulación un torrencial principio de orden público económico que, para salvar la premisa del desarrollo sostenible, va a deprimir sensiblemente las adquisiciones de los derechos sociales fundamentales de los trabajadores en los sectores público y privado. Las campanas del debilitado Estado de Bienestar tocan a muerto y las paredes del sistema se agrietan peligrosamente. El economicismo de toda la vida está armado para ganar las batallas libradas en pro de esa consigna. Pese al valioso efecto de la recepción de los derechos sociales fundamentales de los trabajadores en la UE, retornan estos al estado de pariente pobre que los estigmatizaba de antiguo. El sugestivo lema que, en pro de la irregresividad de las victorias sociales de los sindicatos, rezaba «... siempre más, nunca bastante...», cede ante la predicción vetotestamentario que lamenta cómo «... al que mucho o casi todo lo posee, todo le será dado, y al que poco o casi nada tiene, todo le será quitado».

Puede seguirse discutiendo que Europa no sea hoy ni haya sido jamás un continente, una cultura, un pueblo o una historia, ni que posea una frontera única, ni que venga de un sueño o un destino comunes. Acaso haya Europa $(s)$ concurrentes que requieren análisis profundos para dilucidar y hacer saber sus rasgos individualizadores. Pero es evidente que el trazado -modélico y básico- del orden mundial solamente se entiende en función de las luces y las sombras del pensamiento europeo, y de un ingenio que, a empellones de la propia conciencia, ha situado en vanguardia de sus adquisiciones el reconocimiento de los derechos sociales fundamentales de los trabajadores.

Ello acontece en el solar de Europa, donde emergieron y maduraron las aspiraciones de agotar la curiosidad intelectual y adueñarse de sus yacimientos, de difundir las lenguas para perpetuar la comunicación y la satisfacción de dialogar, de propagar universalmente las ideas para poner a prueba su eficacia, y de impulsar, en fin, las acciones de las mujeres y los hombres que han cooperado a realizarlas, y las de cuantos, al sucederles y repoblar sus espacios habitables, han sido y siguen siendo sus imitadores. 


\section{Bibliografía de orientación}

ALDECOA, F. «El Tratado de Niza, consolidación y reforma de la Unión Europea», Cuadernos Europeos de Deusto, n. ${ }^{\circ} 25$, pp. 185-210.

Alonso Olea, M. «La Unión Europea y la Política Social», España y la Unión Europea: Las consecuencias del Tratado de Maastricht, pp. 5889. Madrid: Ed. Círculo de Lectores, 1992.

Attali, J. Europe (s). París: Ed. Fayard, 1994.

CANedo, J. R. y GoRdillo, L. «Los derechos fundamentales en la Unión Europea a la espera de Lisboa», Cuadernos Europeos de Deusto, n. ${ }^{\circ} 39$, 2008, pp. 25-57.

CRESPO, S. «Algunas reflexiones sobre el espacio social europeo», Política Social de la Comunidad Europea, v. 1, pp. XV-XXXII. Madrid: Ed. Ministerio de Trabajo y Seguridad Social, 1989.

Drouin, P. L'Europe du Marché comun. París: Ed. Julliard, 1968.

FAVAREL-DAPAS, B. «L'Europe sociale», L'Union Europeenne, pp. 26-35. París: Ed. La documentation française, 2004.

García DE ENTERria, E. et al. «Le développement de la politique sociale européenne», Rapport du comité des Sages, Bruselas-Luxemburgo: Ed. Comisión Europea, 1996.

IsSAC, G. Manual de Derecho Comunitario general, traducción de BIGNOZZI, J. y MARFA, J. Barcelona: Ed. Ariel, 1985.

LOPEZ GARRIDO, D. El Tratado de Maastricht. Madrid: Ed. El autor, 1992.

LouIs, J. V. El ordenamiento jurídico comunitario, traducción y edición de la Oficina de Publicaciones de la Comisión de las Comunidades Europeas, Bruselas-Luxemburgo, 1985.

Lyon-Caen, G. Droit social international et européen. París: Ed. Dalloz, 1979.

Mariscal, N. Más allá de Lisboa: Horizontes europeos. Madrid: Ed. Tecnos, 2010.

MoravcsiK, A. The Choice for Europe: Social Purpose and State Power. Londres: Ed. UCL Press, 1999.

MuÑoz DE Bustillo, R. «La viabilidad del Estado de Bienestar en un contexto hostil», Cuadernos Europeos de Deusto, n. ${ }^{\circ} 28,2003$, pp. 33-55.

PÉREZ DE las HERAS, B. «Reestructuración de Tratados y visibilidad jurídica en la Unión Europea», Cuadernos Europeos de Deusto, n. ${ }^{\circ}$ 30, 2004, pp. 163-180.

Sala, T. et al. Derecho Social Comunitario. Valencia: Ed. Tirant lo Blanch, 1995.

ZorriLla, M. M. «Luces y sombras de la Europa social», Estudios de Deusto, v. 47/1, 1999, pp. 173-199. 